had some large spears, armed with flint, differing little from those of Moustier. But nearly all their weapons were light, and the deer-horn points replaced the flint points of an earlier epoch.

The bow had become the predominant weapon, for henceforth nothing resisted man; all fled before him, and hunting was no longer a struggle but a chase. There were two kinds of arrows: the little pointed arrow, not barbed, for small animals and birds, and the large dart with two sets of barbs, which was principally used in hunting the reindeer. Light spears, terminating in a flattened point, darts with conical points, and long sharp poignards, which gave, when necessary, the finishing blow, completed the hunting equipment. I was nearly fo'getting the rallying whistle. It was a reindeer's phalange, pierced near one end, with an oblique hole which did not go right through, and only penetrated to the medullary canal. By blowing on this hole as on a drilled key, one can, even to this day, extract shrill sounds.

(To be continued.)

\section{THE NEW HYDROCARBON GAS}

THE new hydrocarbon gas produced by Mr. Ruck's process certainly promises to realise the conception that has long floated in the minds of scientific men of turning the exhaustless store of heating power to account that lies ready to hand in water. Mr. Ruck appears literally, by the successful development of his invention, to have set the Thames on fire. At this present time, at the Battersea water-works, on the banks of the old river, near to Battersea Park, both light and heat may be seen and felt in the process of evolution from the decomposition of the water of its stream, and further light is added to the gas first produced by a very simple and uncostly extension of the process, until the illuminating power is raised to the intensity requisite for artificial lighting during the dark hours of the night. The Battersea water-works are now lit experimentally by this new form of gas, an apparatus having been erected there to test and prove the efficiency and value of the method.

Mr. Ruck's hydrocarbon gas, it should be at once understood, differs entirely from the so-called "air gases" that consist mainly of air impregnated with the vapour of some form of naphtha or petroleum, in the fact that its base is essentially a gas. The heating gas, which is the form first generated, is true honest hydrogen mingled with a little taint of carbonic oxide, and a small and practically unimportant percentage of carbonic acid ; and the apparatus by which this heating gas is produced is remarkably ingenious and simple. Ordinary steam is brought through a pipe from one of the boilers of the engine house, and this steam is poured through a horseshoe-shaped tube that passes through the red heat of a fierce coke furnace. In this tube it is superheated, or raised to a temperature which disposes its constituents, the oxygen and hydrogen, to dissolve their intimate alliance, and in that state it is parsed on into retorts, also contained in a lower region of the same furnace, which are packed full of coke and fragments of iron. The steam is discharged into the interior of these retorts out of its own conducting pipe, so that it has to traverse their entire length amidst the masses of heated metal and coke, and during its journey it ceases to be steam. The oxygen attaches itself to the iron, and forms scales of black rust, and the hydrogen passes on free, with only a commingling with carbonic oxide and carbonic acid formed by the action of the disengaging oxygen upon the coke packing of the retort, and with certain sulphurous vapours that also issue from the coke. In this impure state the gas issues from the retort, and is carried to a purifying chamber containing oxide of iron, which at once clears it from all the sulphur compounds, and it is then stored in a gas reservoir of ordinary form. In this state it is the "heating gas ; that is, gas supereminently suited for all purposes where heat, without light, is required, as, for instance, for gas stoves of whatever kind, or for boiling water, and generating steam. When the gas is taken from this reservoir, and discharged through an ordinary burner, it burns with the pale colourless hydrogen flame, streaked with a few lines, of yellow scintillations, and of the characteristic pale green colour of incandescent carbonic oxide.

At the present time, with coals quoted in the London markets at $52 s$. per ton, this part of the affair, the production of a heating gas out of water, at the cost of a very simple apparatus, a very small consumption of fuel, and with a demand for an incredibly small application of manual labour, seems to be the one that is most deserving of thought and attention. In the practice of the manufacture at the Battersea water-works, by the expenditure of one ton of coke for the interior of the retorts, and of two tons of coke for the support. of the heat of the furnace, 133,000 cubic feet of gas are produced, that, to say the least of it, is quite equal for all purposes of heating to coal gas in ordinary use, and that is as chemically enduring and perfect for storing in gasometers and for transmission to unlimited distances through pipes. In a direct experiment with the gas, tried by the writer, one quart of cold water was boiled in four minutes and a half by a jet of flame issuing from an orifice one-eighth of an inch in diameter, and under a pressure of three inches of water, without any arrangement for the concentration and protection of the flame from chill and draughts. There was no provision on band to measure the exact consumption of the gas, but the man who was engaged in the Laboratory estimated it at about five cubic feet per hour. Now the cost of this gas at the works is found to be $7 d$. per $\mathrm{r}, 000$ cubic feet. In this experiment, therefore, the result was something like converting seven gallons of water at a temperature of $38^{\circ}$ Fahrenheit, into boiling water for $\mathrm{I} d$. One thousand cubic feet at a cost of $7 d$. would boil about 50 gallons of cold water. At the works at the present time the steam is supplied independently from the boiler of the engine room. But this does not need to be taken into consideration, because the waste heat of the retort furnace is more than enough for the production of the steam, and in ordinary circumstances will be used, as a matter of course, for the purpose.

When it is desired to use the gas for lighting purposes, it has to be further prepared and manipulated. The "heating gas" from the gasometer is made to bubble through a reservoir containing rectified petroleum at a specific gravity of about 0.680 . It then passes at once into the pipes for circulation and consumption, and issues from these burners a very excellent gas, equal in illuminating power to $16 \frac{1}{2}$ candles with a consumption of 5 cubic feet an hour in an Argand burner. The cost of the gas in this form is a trifle less than $I s .8 d$. per 1,000 cubic feet, and the saving in the manufacture over ordinary coal gas with coals costing $26 s$. per ton, is estimated to be 40 per cent. -in exact figures is. $8 d$. per 1,000 cubic feet against $2 s .4 d$. per 1,000 cubic feet. One thousand cubic feet of the heating gas require a gallon and a half of the petroleum to convert them into illuminating gas, but they are considerably increased in volume by the conversion133,000 cubic feet of "heating gas" become 165,000 cubic feet of "illuminating gas" after it has been passed through the petroleum. Arrangements have been made for the purchase of several millions of tons of crude petroleum at a price which will represent a cost of $6 d$. a gallon after rectification.

Some rather severe experiments have been already tried to test the power of the illuminating gas to retain its full charge of carbon after travelling through long distances of delivery at low temperatures, and the report of the testing engineers is that so far the experiment was 
eminently satisfactory, and that there was no perceptible loss of illuminating power. Experiments on this point, however, and also upon the arrangements that will best cnable the heating gas to be turned to account, are still in progress, and will afford ground for further notice in duc time.

The furnace and retorts which are at work at Battersea are very compact, occupying about the space of an ordinary well-packed steam engine of 20 or 30 horse power. These retorts however are only in use for about two hours out of the twenty-four to supply the works with illumination, and it is estimated that they would be quite large enough to supply illuminating gas for the consumption of a small town of about 4,000 inhabitants. As regards the most important bearing of saving of manual labour it is found to amount to dispensing with the services of 29 labourers out of every 30 who are required in the old process of coal distillation. The charge of coke and iron which is now in the retorts yielding the gas at Battersea has not been changed, or renewed, for several weeks. The iron in the retorts is in the form of old chain, for the convenience of withdrawal, and seems to cover itself with thin black scales. The carbon in the interior of the retort is removed entirely by the gas as it is gradually converted in the process of manufacture into carbonic acid and carbonic oxide.

It may, perhaps, be well to remark that a process for the manufacture of "water gas" was presented by $M$. Gillard some fourteen years ago, in which superheated steam was decomposed in retorts by the action of incandescent charcoal; the carbonic acid, so formed, issued from the retort with the hydrogen, and was afterwards removed in a special purifier. Lighting power was secured by heating platinum wire in the flanie. The distinctive features of Mr. Ruck's process are-the decomposition of the superheated flame by coke and iron, which remain long periods in the retorts without change; the removal of sulphur products by oxide of iron; and the carbonising for illumination by passing the hydrogen through reciifed petroleum.

\section{HUNTERIAN LECTURES BY PROF. FLOWER}

\section{LECTURES I. II. III.}

$\mathrm{T}$ considering the various formations which compose the earth's crust, it is unnecessary, whilst speaking of the mammalia, to refer to rocks lower than those of the secondary formation, for no palæozoic mammals are known. Respecting the value of palæontology in supporring or disproving the various theories at present in vogue regarding the origin of life, the details of the course will supply evidence of value. The amount of "the imperfection of the geological record "will be demonstrated in the classes considered. The extreme unlikelihood of any aërial animals being preserved in the fossil state is scarcely realised by many, nor is the smallness of the extent of the surface of the earth which has been examined. An accidental discovery like that in the upper oolite, of an extremely small deposit containing numerous marsupial remains, has done more to throw light on the subject than many more painstaking researches over lirger fields. These facts being taken into consideration, it is clear that if it can be shown that the examination of fossil remains indicates only a tende cy towards the filling of the gaps between existing groups, the tendency will be strongly in favour of evolution; but if it brings to light nothing but types which are entirely new, the doctrine of special creations will be supnorted. Prof. Huxley has been able to show many of the transitions between reptiles and birds, and Prof. Marsh's new discovery of udontornis is an important addition. It is among mammalia that in the present state of our knowledge there are the greatest gaps. The relations of the Cheiroptera are indeterminable, and so are those of the Edentata; not much is known of the Cetacea as regards their affinities, though they may be near the seals on the other hand. The Ungulata constitute a group in which the considerable gaps between existing types are almost completely removed by the study of fossil forms. Taking first the Perissodactylata, in the Pliocene. Equidæ abounded in America as well as in the Old World. Tapirs and Rhinoceroses were equally abundant; these are the remnants of a large group which is probably becoming extinct, as it is indicated by the fact that the species are becoming less numerous. A little further back we find Hipparion with rudimentary side toes. In the Miocene and upper Eocene, Anchitherium and Palæotherium represent the group, though the latter is peculiar in its teeth. Fossil Rhinoceroses have larger teeth and no horn, some possess incisors, and the other teeth less specialised. The Tapir stands much by itself, and an ancient type containing Lophiodon and Hyracotherium seems to be now unrepresented. Again, among the Artiodactylates, Charopotamus and Hyopotamus as far back as the Eocene are the most generalised, and from them as we ascend in the series the differentiation towards existing types becomes more and more evident. Among these later forms the North American Oreodon, which has been obtained in such great numbers, tends to the ruminants, but possessed upper incisors and canines. The Miocene of France and Germany affords very similar evidence. It is also interesting to note that the further we go back, the more do the individuals of the Perissodactylate group approach the Artiodactylates, but as yet no connecting link has been obtained. The Proboscidia, animals first appearing in the Miocene, approach in the older forms to the Ungulata, and Prof. Marsh's newly discovered Dinoceras seems to help to fill the gap.

In reviewing the various strata which are found to contain remains of mammalia, those of the quaternary or post-pliocene period are rich in species not far removed from existing forms. In mo it countries where limestone rocks exist, caverns are found containing large numbers of bones, such as those of Kirixdale, Liege, and Gibraltar, the last having been lately explored by Mr. Busk. Those of the Wellington Valley in Australia have afforded numerous remains of marsupials, showing that those animals have been located there for a considerable period. Again from the Pampas of South America many of the valuable skeletons which enrich the collection of the College of Surgeons have been obtained. The Miocene formation is particularly interesting from the richness of its fauna. Dinotherium and Mastodon being obtained in South France, as well as at Pikermé in Greece, where they are associated with Hipparion, the giraffe and others. Belonging to the same formation are the strata of the Siwalik Hills of India, which abound in hoofed animals, and have been so well worked out by Dr. Falconer. The peculiar mammalia of the territory of Nebraska, at the foot of the Rocky Mountains, belongs to the same age. In the Eocene period lived the animals so fully described by Cuvier, Palaotherium, Anoplotherium, \&c. Besides in the Paris basin, similar strata occur at Hordwell, in Hants, and at Binstead, Bembridge, and Headon, in the Isle of Wight. In the London Clay of Sheppey Hyracotherium and Lophiod. $n$ are found.

Early in this century, it was supposed that mammalia were not present in the secondary rocks; but this was shown to be incorrect. In 1847, Prof. Plieninger discovered in some Triassic sand he was sifting a minute tooth with double fangs, probably belonging to some marsupial animal, which he named Microlestes. Prof. Owen considers it to be related to Myrmecobius. Similar teeth from the Rhaetic beds have been discovered by Mr. C. Moore, of Bath. An equally minute Triassic tooth was found by Mr. Boyd Dawkins at Watchet, in Somersetshire, and from its slight resemblance to that of Hypsiprymnus it has been named 